\title{
Health benefits of nuts: potential role of antioxidants
}

\author{
Rune Blomhoff ${ }^{1} *$, Monica H. Carlsen ${ }^{1}$, Lene Frost Andersen ${ }^{1}$ and David R. Jacobs $\mathrm{Jr}^{1,2}$ \\ ${ }^{1}$ Department of Nutrition, Institute of Basic Medical Sciences, University of Oslo, Oslo, Norway \\ ${ }^{2}$ Division of Epidemiology and Community Health, School of Public Health, University of Minnesota, Minneapolis, \\ MN 55454-1015, USA
}

\begin{abstract}
A diet rich in fruits, vegetables and minimally refined cereals is associated with lower risk for chronic degenerative diseases. Since oxidative stress is common in chronic degenerative disease, it has been assumed that dietary antioxidants may explain this protective effect. Every dietary plant contains numerous types of antioxidants with different properties. Many of these antioxidants cooperate in oxidative stress reduction in plants, and we hypothesize that many different antioxidants may also be needed for the proper protection of animal cells. To test this hypothesis, it is useful to identify dietary plants with high total antioxidant content. Several nuts are among the dietary plants with the highest content of total antioxidants. Of the tree nuts, walnuts, pecans and chestnuts have the highest contents of antioxidants. Walnuts contain more than 20 mmol antioxidants per $100 \mathrm{~g}$, mostly in the walnut pellicles. Peanuts (a legume) also contribute significantly to dietary intake of antioxidants. These data are in accordance with our present extended analysis of an earlier report on nut intake and death attributed to various diseases in the Iowa Women's Health Study. We observed that the hazard ratio for total death rates showed a U-shaped association with nut/peanut butter consumption. Hazard ratio was 0.89 $(\mathrm{CI}=0.81-0.97)$ and $0.81(\mathrm{CI}=0.75-0.88)$ for nut/peanut butter intake once per week and 1-4 times per week, respectively. Death attributed to cardiovascular and coronary heart diseases showed strong and consistent reductions with increasing nut/peanut butter consumption. Further studies are needed to clarify whether antioxidants contribute to this apparent beneficial health effect of nuts.
\end{abstract}

Nuts: Antioxidants: LDL oxidation: Flavonoids: FRAP: Antioxidant defence: Oxidative damage

Nuts are not easily defined in a manner that would be both compatible with popular usage and acceptable to botanists. For example, the groundnut or peanut is a legume, and the chufa nut, which is common in south Europe and Africa, is a tuber. Some languages such as French, even lack an umbrella word equivalent to nuts. 'Noix' in French looks like one, but just means walnuts. In this text we will not only include botanically defined nuts, but will also include data on some foods which have traditionally been defined as nuts.

Nuts are highly nutritious and of prime importance for people in several regions in Asia and Africa. Most nuts contain a great deal of fat (e.g. pecan $70 \%$, macadamia nut $66 \%$, Brazil nut $65 \%$, walnut $60 \%$, almonds $55 \%$ and peanut butter $55 \%$ ). Most have a good protein content (in the $10-30 \%$ range), and only a few have a very high starch content (Davidson, 1999). Recently, many nuts have also been identified as especially rich in antioxidants (Halvorsen et al. 2002; Wu et al. 2004). Nuts therefore constitute one of the most nutritionally concentrated kinds of food available. Most nuts, left in their shell, have a remarkably long shelf-life and can conveniently be stored for winter use.

The aim of this paper is first to present the importance of antioxidants and oxidative stress for human disease, and second to report new data on the antioxidant content of various nuts. We also extend the analysis of Ellsworth et al. (2001) concerning the association between nut intake and death attributed to various diseases in the Iowa Women's Health Study (IWHS).

\section{Non-enzymatic oxidative damage and oxidative stress}

Free radicals and other reactive oxygen and nitrogen species (ROS and RNS) are formed as a result of normal cellular oxidative metabolic reactions. Such molecules are also formed as a consequence of diseases (e.g. inflammations) and from tobacco smoke, environmental pollutants, natural food constituents, drugs, ethanol and radiation. If not quenched by antioxidants, these highly reactive compounds will react non-enzymatically with, and potentially alter the structure and function of, several cellular or extracellular components, such as cell membranes, lipoproteins, proteins, carbohydrates, RNA and DNA (Halliwell, 1996; Sies, 1997; Beckman \& Ames, 1998; Gutteridge \& Halliwell, 2000; McCord, 2000).

When the critical balance between the generation of free radicals and other ROS or RNS and the antioxidant defences is unfavourable, oxidative damage can accumulate. Oxidative stress is defined as 'a condition that is characterized by accumulation on non-enzymatic oxidative damage to molecules that threaten the normal function of the cell or the organism' (Blomhoff, 2005). Compelling evidence has emerged in the last two decades demonstrating that oxidative stress is intimately involved in the pathophysiology of many seemingly unrelated types of disease. Thus, oxidative stress 
is now thought to significantly contribute to all inflammatory diseases (e.g. arthritis, vasculitis, glomerulonephritis, lupus erythematosus, adult respiratory distress syndrome), ischemic diseases (heart disease, stroke, intestinal ischemia), cancer, hemochromatosis, acquired immunodeficiency syndrome (AIDS), emphysema, organ transplantation, gastric ulcers, hypertension and preeclampsia, neurologic diseases (multiple sclerosis, Alzheimer's disease, Parkinson disease, amyotrophic lateral sclerosis, muscular dystrophy), alcoholism, smokingrelated diseases and many others (see Halliwell, 1996; Sies, 1997; Beckman \& Ames, 1998; Gutteridge \& Halliwell, 2000; McCord, 2000;Blomhoff, 2005 for reviews).

\section{Antioxidant defence}

The term 'antioxidant' cannot be defined purely chemically; it is always related to the cellular or organismal context, and to oxidative stress. Moreover, every molecule can be both an oxidant and a reductant; this is determined by the reduction potential of the molecule with which it reacts. An antioxidant is therefore defined as 'a redox active compound that limits oxidative stress by reacting non-enzymatically with a reactive oxidant', while an antioxidant enzyme is 'a protein that limits oxidative stress by catalysing a redox reaction with a reactive oxidant' (Blomhoff, 2005).

A complex endogenous antioxidant defence system has been developed to counteract oxidative damage and oxidative stress. Such an antioxidant defence is essential for all aerobic cells. The endogenous antioxidant defence has both enzymatic and non-enzymatic components that prevent radical formation, remove radicals before damage can occur, repair oxidative damage and eliminate damaged molecules (Halliwell, 1996; Gutteridge \& Halliwell, 2000; Lindsay \& Astley, 2002). The endogenous antioxidant defence, which is produced by cells themselves, consists of components such as glutathione, thioredoxin and various antioxidant enzymes. Mutations in genes coding for these peptides or proteins often lead to increased incidence of oxidative stress-related diseases as well as premature death (Dalton et al. 2004; Selverstone et al. 2005).

In addition to endogenous antioxidant defence, it has been hypothesized that dietary components may also contribute to antioxidant defence either by providing redox active compounds that can directly scavenge or neutralize free radicals or other ROS and RNS, or by providing compounds that can induce the gene expression of the endogenous antioxidants (Blomhoff, 2005; Moskaug et al. 2005).

\section{Dietary compounds with the ability to induce the production of endogenous antioxidants}

An important antioxidant defence mechanism involves detoxification enzymes such as catalase, several types of glutathione peroxidase and superoxide dismutase, the glutathione S-transferase family, $\gamma$-glutamyl cysteine synthetase and NAD $(\mathrm{P}) \mathrm{H}$ : quinone reductase (quinone reductase) (Fahey et al. 1997; Talalay, 2000; McEligot et al. 2005). Many of these enzymes are generally referred to as phase two enzymes because they catalyze the conversion of xenobiotics, mutagenic metabolites or their precursors to compounds that are more readily excreted. It is believed that if benign or non-damaging plant compounds induce the phase two enzymes, cells are more readily able to neutralize toxic agents such as free radicals and other toxic electrophiles when they appear.

The major plant compounds believed to be able to support the antioxidant defence via this mechanism include the glucosinolates and several other sulphur-containing plant compounds. Glucosinolates are widespread plant constituents, and it is believed that glucosinolate breakdown products (such as the isothiocyanate sulphoraphane) induce phase two enzymes and are therefore responsible for the protective effects shown by Brassica vegetables (Fahey et al. 1997; Talalay, 2000; Lindsay \& Astley, 2002). Allium vegetables contain a number of other sulphur-containing compounds that may also induce phase two enzymes. These compounds include the cysteine sulphoxides and the dithiolthiones. Like the glucosinolates, the active principles found in allium vegetables result from enzymatic degradation of the plant compounds (Fahey et al. 1997; Talalay, 2000; Lindsay \& Astley, 2002).

Dietary plants rich in compounds that induce phase two detoxification enzymes include broccoli, Brussels sprouts, cabbage, kale, cauliflower, carrots, onions, tomatoes, spinach and garlic. The evidence for phase two enzyme inductions at ordinary intake levels of plant foods in humans is, however, limited, and the importance of this defence mechanism in the overall protection against oxidative damage is still uncertain.

\section{Dietary compounds with the ability to directly scavenge or neutralize reactive oxidants}

In addition to the well-known antioxidants, vitamin $\mathrm{C}$, vitamin $\mathrm{E}$ and selenium, there are numerous other antioxidants in dietary plants. Carotenoids are ubiquitous in the plant kingdom, and as many as 1000 naturally occurring variants have been identified. At least sixty carotenoids occur in the fruit and vegetables commonly consumed by humans (Lindsay \& Astley, 2002). Besides the provitamin A carotenoids, $\alpha$ - and $\beta$-carotene and $\beta$-cryptoxanthin, lycopene and the hydroxy-carotenoids (xanthophylls) lutein and zeaxanthin are the main carotenoids present in diet. Their major role in plants is related to light harvesting as auxiliary components and quenching of excited molecules that may be formed during photosynthesis (Halliwell, 1996; Gutteridge \& Halliwell, 2000; Lindsay \& Astley, 2002).

Phenolic compounds are also ubiquitous in dietary plants (Lindsay \& Astley, 2002). They are synthesized in large varieties belonging to several molecular families, such as benzoic acid derivatives, flavonoids, proanthocyanidins, stilbenes, coumarins, lignans and lignins. Over 8000 plant phenols have been isolated. Plant phenols are antioxidants by virtue of the hydrogen-donating properties of the phenolic hydroxyl groups (Lindsay \& Astley, 2002).

Glutathione, thioredoxin and many antioxidant enzymes are present in abundant amounts in the diet. However, they are not absorbed as such from the diet but broken down into their constituent amino acids by digestion. The dietary availability of sulphur amino acids can, however, modulate the cellular glutathione production (Halliwell, 1996; Gutteridge \& Halliwell, 2000; Lindsay \& Astley, 2002).

It was initially thought that supplementation of a single antioxidant such as ascorbic acid, $\alpha$-tocopherol or $\beta$-carotene 
would neutralize free radicals and other ROS or RNS and thereby avoid any oxidative damage. The first strategy for testing this hypothesis was, therefore, to study the ability of these antioxidants to inhibit oxidative damage/stress in cell-free experiments, cell cultures and experimental animals. Such experiments generated many positive results (McCord, 2000; Brigelius-Flohe et al. 2002; Cooper et al. 2004). Moreover, observational epidemiological studies generally support the hypothesis that the intake of foods rich in these antioxidants is associated with reduced oxidative stress-related diseases (Cooper et al. 2004; Stanner et al. 2004). However, large randomized intervention trials that have been conducted to further test the protective effect of individual antioxidant compounds have not been supportive (Albanes et al. 1996; Omenn et al. 1996a, 1996b; Rapola et al. 1997). Several reviews and meta-analyses have recently concluded that, for most forms of oxidative-stress-related diseases tested so far, there is no beneficial effect of supplemental $\alpha$-tocopherol or, probably, of supplemental $\beta$-carotene and ascorbic acid (Vivekananthan, 2003; Eidelman et al. 2004; Shekelle et al. 2004). The results of intervention studies using supplements of selenium, which is not an antioxidant itself but an essential building block of the endogenous antioxidant defence, are more positive, however (Bjelakovic et al. 2004; Etminan et al. 2005).

The conclusion that antioxidant supplements do not contribute to the beneficial effects of fruits and vegetables is probably premature. One explanation could be that the beneficial health effect arises from the contribution made by other antioxidants in fruits and vegetables. There are numerous antioxidants in dietary plants, and only a small number of the antioxidants in most dietary plants are contributed by $\alpha$-tocopherol, ascorbic acid and $\beta$-carotene. There is a distinct possibility that some of these antioxidants, whose role in living plants is pathogen protection and oxidative stress reduction, can do better in randomized intervention trials than $\alpha$-tocopherol, ascorbic acid and $\beta$-carotene.

\section{Antioxidant network}

An alternative antioxidant hypothesis is built on the observation that antioxidants, which cooperate in an integrated manner in plant cells, may also cooperate in animal cells. A network of antioxidants with different chemical properties may, therefore, be needed for proper protection against oxidative stress (Jacobs \& Steffen, 2003; Blomhoff, 2005). The concerted action from a number of dietary antioxidants should be expected from the complex physical structure that constitutes a human being. The human body, its tissues and organs, cells and macromolecules, consists of phases with a range of physical variables, anatomical subdivisions, and water- and lipid-soluble phases. Within these phases, and at interfaces between phases, there are numerous chemical variables, such as $\mathrm{pH}$, ionic strength, osmolality, electrical charge and chemical concentration. These variables influence the ability of the phases to act as solvents for lipid- and water-soluble antioxidants. As some water-soluble antioxidants have low partition coefficients into a lipid-soluble phase, their entry or retention in a water-soluble phase will depend on their $\mathrm{pKa}$ and the $\mathrm{pH}$ gradient across the membrane. In addition, antioxidants with both hydrophobic and hydrophilic characteristics may be distributed between water- and lipid-soluble phases depending on the relative contribution and stereochemistry of hydrophobic and hydrophilic substitutions. Solubility is further modified when an antioxidant is conjugated or bound into more complex substances such as proteins. Although it would be much simpler to test the protective effect a of single or of a limited number of antioxidants, we may never find such an association if it is actually true that maybe hundreds of dietary antioxidants, such as carotenoids, polyphenolic acids, sulfides, flavonoids and lignans, are bioactive and work synergistically.

One theoretical, but likely, possibility is that antioxidants with different partition coefficients recharge neighbouring antioxidants in an integrated and complementary manner. Such interactions have been proven in vitro for $\alpha$-tocopherol, $\alpha$-tocotrienol, vitamin $\mathrm{C}$, lipoic acid and thiols by Packer and colleagues (Packer et al. 2001). Flavonoids from almonds have also been shown to act in synergy with vitamin $\mathrm{C}$ and vitamin $\mathrm{E}$ and other bioactive plant compounds to enhance LDL resistance to oxidation (Chen et al. 2005).

\section{A total antioxidant food table}

A diet containing a high total content of antioxidants and a variety of different antioxidants may therefore yield the best protection against oxidative-stress-related diseases. A ranked table with the total concentration of redox-active antioxidants of various foods was, therefore, considered a useful tool for testing alternative antioxidant hypotheses.

In previous studies, three methods were used to assess total antioxidant capacity in dietary plants: the 6-hydroxy2,5,7,8-tetramethylchroman-2-carboxylic acid (Trolox) equivalent antioxidant capacity (TEAC) assay of Miller et al. (1996), the ferric reducing ability of plasma (FRAP) assay of Benzie \& Strain (1996), and the oxygen radical absorbance capacity (ORAC) assay of Glazer's laboratory (DeLange et al. 1989) and others (Cao et al. 1993). The TEAC and the ORAC assay are based on the antioxidant's ability to react with or neutralize free radicals generated in the assay systems, while the FRAP assay measures the reduction of $\mathrm{Fe}^{3+}$ (ferric iron) to $\mathrm{Fe}^{2+}$ (ferrous iron) in the presence of antioxidants. Since the ferric-to-ferrous iron reduction occurs rapidly with all reductants with half-reaction reduction potentials above that of $\mathrm{Fe}^{3+} / \mathrm{Fe}^{2+}$, the values in the FRAP assay express the corresponding concentration of electron-donating antioxidants.

For several reasons we selected the FRAP analysis, which measures both water- and fat-soluble antioxidants (Halvorsen et al. 2002; Dragland et al. 2003; Blomhoff, 2005). A major advantage of the FRAP method is its ability to quantify the amounts of total antioxidants or reductants in foods. Values generated by the FRAP method can, therefore, be used to calculate the total intake of antioxidants and the contributions by various food groups to total dietary intake. The FRAP assay is also the only one to directly measure antioxidants or reductants in a sample. The other assays are more indirect because they measure the inhibition of reactive species (free radicals) generated in the reaction mixture. These results also strongly depend on the type of reactive species used. The FRAP assay, in contrast, uses antioxidants as reductants in a redoxlinked colorimetric reaction. Moreover, the other assays (but not FRAP) use a lag phase type of measurement. In previous experiments this has been difficult to standardize and has 
generated different results between different laboratories. In the FRAP assay, pretreatment is not required, stoichiometric factors are constant and linearity is maintained over a wide range. One possible disadvantage of FRAP is the fact that it does not react with thiols, because the reduction potential for thiols is generally lower than that of the $\mathrm{Fe}^{3+} / \mathrm{Fe}^{2+}$ halfreaction. However, since only limited amounts of plant glutathione are absorbed by humans (Buettner, 1993), and almost no other antioxidant thiols are present in dietary plants (one exception is garlic), the FRAP method may be suitable for assessing total antioxidants in plants. One disadvantage with all of these assays is that they measure the total antioxidant content of foods as eaten, but do not address bioavailability. This problem exists for all nutrients, however, since food tables list quantities of substances as eaten, not post-absorption.

\section{Total amounts of antioxidants in nuts and other dietary plants}

We have systematically assessed total antioxidant content (TAC) in a variety of dietary plants (Halvorsen et al. 2002; Dragland et al. 2003; Blomhoff, 2005). Foods identified by the FRAP assay as containing a high level of total antioxidants include several berries, fruits, nuts, drinks and spices. Table 1 presents TAC values for several nuts while Table 2 contains values for some other antioxidant-rich foods.

Our analyses demonstrate that walnuts contain massive amounts of antioxidants, i.e. more than $20 \mathrm{mmol}$ antioxidants per $100 \mathrm{~g}$. Pecans, chestnuts, peanuts and pistachios are also very rich in total antioxidants with average values of $8 \cdot 3$, $4.7,2.0$ and $1.3 \mathrm{mmol} / 100 \mathrm{~g}$, respectively. Hazelnuts, almonds, Brazil nuts, macadamias, pine kernels and cashew nuts also contained significant amounts of total antioxidants (i.e. 0.3$0.7 \mathrm{mmol} / 100 \mathrm{~g}$ ). Peanut butter, a common form of nut consumption, contains only approximately a quarter of the total antioxidants of peanuts. Though not in the top ranks of antioxidant containing foods, it is still an important contributor.

Remarkably, in walnuts, most of the antioxidants are located in the pellicle and less than $10 \%$ is retained in the walnuts when the skin is removed. In most other cases, nuts without the pellicle contained less than $50 \%$ of the total antioxidants compared to nuts with the pellicle. Also, Brazil nuts and pistachios purchased without the outer shell contained much fewer antioxidants than nuts purchased with the shell. A significant portion of nut antioxidants is therefore located in the pellicle, and nuts stored with the outer shell tend to contain more antioxidants than nuts stored without the shell. The TAC of most nuts are comparable with the TAC of other antioxidant-rich foods (Table 2) and are much higher than the TAC values of foods of animal origin such as meat, cheese and milk, which contain $0 \cdot 0-0 \cdot 1 \mathrm{mmol} / 100 \mathrm{~g}$ (Blomhoff, 2005).

Based on their USDA-specified serving sizes, walnuts, pecans, chestnuts, peanuts, and peanut butter contribute 6.5 , $2.4,1.3,0.6$ and $0.2 \mathrm{mmol}$ antioxidants per serving, respectively. In comparison, other foods that are rich in antioxidants, such as blueberries, cloves, coffee, dark chocolate and red wine, contribute $11.9,9.8,6.7,3.8$ and $3.1 \mathrm{mmol}$ per serving, respectively. The contribution of nut antioxidants to total dietary intake of antioxidants may also be significant, since the daily intake of total antioxidants in cereals, fruits and berries, fruit juices, vegetables, tea and wine each contributes between 0.4-1.5 mmol TAC (Svilaas et al. 2004).

The results shown in Table 1 are mean results based on the analysis of several samples. The full list of results with all individual items is shown in Table 3. As we can see from this table, there are relatively large variations within each nut product. For example, TAC in walnuts with pellicle ranged from 10.8 to $33.3 \mathrm{mmol}$ per $100 \mathrm{~g}$. Hazelnuts and almonds with pellicle ranged from 0.5 to $1.2 \mathrm{mmol}$ and 0.2 to 0.7 per $100 \mathrm{~g}$, respectively. These values suggest that nut variety, cultivation conditions and/or storage conditions

Table 1. Total antioxidant content (TAC) in nuts and nut products

\begin{tabular}{lccc}
\hline Products & TAC (mmol/100 g) & Serving size (g) & TAC (mmol/ serving size) \\
\hline Almonds with pellicle & 0.412 & 28.35 & 0.117 \\
Almonds without pellicle & 0.112 & 28.35 & 0.032 \\
Brazil nuts with pellicle & 0.249 & 28.35 & 0.071 \\
Brazil nuts without pellicle & 0.191 & 28.35 & 0.054 \\
Brazil nuts with pellicle but purchased without outer shell & 0.090 & 28.35 & 0.026 \\
Cashews with pellicle & 0.388 & 28.35 & 0.110 \\
Chestnuts with pellicle & 4.668 & 28.35 & 1.323 \\
Chestnuts without pellicle & 0.755 & 28.35 & 0.214 \\
Hazelnuts with pellicle & 0.701 & 28.35 & 0.199 \\
Hazelnuts without pellicle & 0.160 & 28.35 & 0.045 \\
Macadamia nuts with pellicle & 0.424 & 28.35 & 0.120 \\
Peanut butter & 0.571 & 32 & 0.183 \\
Peanuts with red pellicle & 1.967 & 28.35 & 0.558 \\
Peanuts without pellicle & 0.838 & 28.35 & 0.238 \\
Pecans with pellicle & 8.330 & 28.35 & 2.362 \\
Pine kernels & 0.367 & 28.35 & 0.104 \\
Pistachios with pellicle & 1.274 & 28.35 & 0.361 \\
Pistachios with pellicles but purchased without outer shell & 0.890 & 28.35 & 0.252 \\
Walnuts with pellicle & 23.073 & 28.35 & 6.541 \\
Walnuts without pellicle & 1.131 & 28.35 & 0.321
\end{tabular}

Mean values of items presented in Table 3 are given. Serving size as given by the USDA (U.S. Department of Agriculture, Agricultural Research Service. 2004. USDA National Nutrient Database for Standard Reference, Release 17). 
Table 2. Total antioxidant values in other antioxidant-rich foods

\begin{tabular}{lccc}
\hline Product & TAC $(\mathrm{mmol} / 100 \mathrm{~g})$ & Serving size $(\mathrm{g})$ & TAC (mmol/serving size) \\
\hline Cloves & $465 \cdot 3$ & $2 \cdot 1$ & $9 \cdot 8$ \\
Cinnamon & $98 \cdot 4$ & $2 \cdot 3$ & $2 \cdot 3$ \\
Oregano & $45 \cdot 0$ & $1 \cdot 0$ & $0 \cdot 5$ \\
Blueberry & $8 \cdot 2$ & 145 & $11 \cdot 9$ \\
Blackberry & $5 \cdot 1$ & 144 & $7 \cdot 3$ \\
Raspberry & $3 \cdot 1$ & 123 & $3 \cdot 8$ \\
Strawberry & $2 \cdot 2$ & 166 & $3 \cdot 8$ \\
Dark chocolate $(70 \%$ cocoa $)$ & $13 \cdot 4$ & $28 \cdot 35$ & $3 \cdot 8$ \\
Red grapes & $2 \cdot 4$ & 160 & $1 \cdot 5$ \\
Orange & $1 \cdot 1$ & $140(1 \mathrm{fruit})$ & $3 \cdot 1$ \\
Red Wine & $2 \cdot 9$ & $103(1 \mathrm{glass})$ & $2 \cdot 0$ \\
Grape juice (blue) & $1 \cdot 6$ & $249(240 \mathrm{ml})$ & $6 \cdot 7$ \\
Orange juice & $0 \cdot 8$ & $249(240 \mathrm{ml})$ & $6 \cdot 0$ \\
Black coffee, filtered & $2 \cdot 8$ & $240(240 \mathrm{ml})$ & $1 \cdot 9$ \\
Green tea & $2 \cdot 5$ & $240(240 \mathrm{ml})$ & \\
Black tea & $0 \cdot 8$ & $240(240 \mathrm{ml})$ & \\
\hline
\end{tabular}

The serving size of each food is in accordance with the USDA National Nutrient Database for Standard Reference (USDA, Agricultural Research Service. 2004. USDA National Nutrient Database for Standard Reference. Release 17.)

markedly modify the content of total antioxidants. Nuts with much higher antioxidant contents could reach the market and be available for human consumption if these parameters were systematically optimized.

\section{Types of antioxidants found in nuts}

Nuts contain numerous types of antioxidants. In almonds, for example, there is a range of flavonoids, including catechins, flavonols and flavonones in their aglycone and glycoside forms (Sang et al. 2002; Frison-Norrie et al. 2002). Peanuts and pistachios contain several flavonoids and are rich in resveratrol (Lou et al. 2001), while walnuts contain a variety of polyphenols and tocopherols. Polyphenols in walnuts are typically non-flavonoid ellagitannins (Anderson et al. 2001). Alkyl phenols are found in abundance in cashews (Trevisan et al. 2005).

\section{Protective effects of nut antioxidants on LDL oxidation in in vitro experiments and animal models}

Nuts probably have favourable effects on cardiovascular diseases through several mechanisms. These effects may be mediated by their fatty acid profiles, fibre or antioxidant contents, or by a combination of these mechanism. Several recent observations suggest that nut antioxidants have interesting biological effects that may be related to a favourable effect on cardiovascular diseases (Mukuddem-Petersen et al. 2005). Anderson et al. (2001) used polyphenol-rich extracts from English walnuts and ellagic acid and studied both their ability to inhibit LDL oxidation in vitro and their effects on LDL alpha-tocopherol during oxidative stress: 2,2'-Azobis'(2-amidino propane) hydrochloride-induced LDL oxidation was significantly inhibited by 87 and $38 \%$ with the highest concentration (1.0 micromol/l) of ellagic acid and walnut

Table 3. Variations in antioxidant content of nuts (from different countries and geographic sources)

\begin{tabular}{|c|c|c|c|c|}
\hline \multirow[b]{2}{*}{ Product } & \multirow[b]{2}{*}{$\mathrm{n}$} & \multicolumn{3}{|c|}{ FRAP mmol/100 g } \\
\hline & & Mean $\pm \mathrm{SD}$ & Range & Origin \\
\hline Almonds with pellicle & 9 & $0.41 \pm 0.16$ & $0.18-0.67$ & USA, Spain, Norway, Australia, \\
\hline Almonds without pellicle & 5 & $0.11 \pm 0.02$ & $0.09-0.13$ & USA, Unknown, Norway \\
\hline Brazil nuts with pellicle & 5 & $0.15 \pm 0.09$ & $0.01-0.26$ & USA, Norway, Unknown \\
\hline Brazil nuts without pellicle & 2 & $0.19 \pm 0.05$ & $0.09-0.24$ & USA, Unknown \\
\hline Cashews & 3 & $0.39 \pm 0.18$ & $0.23-0.64$ & USA \\
\hline Chestnuts without pellicle & 1 & 0.75 & - & Italy \\
\hline Hazelnuts with pellicle & 5 & $0.70 \pm 0.28$ & $0.49-1.24$ & USA, Norway \\
\hline Hazelnuts without pellicle & 1 & 0.16 & - & USA \\
\hline Macadamia nuts & 4 & $0.42 \pm 0.12$ & $0.25-0.59$ & USA, Norway, Australia \\
\hline Peanut butter & 6 & $0.57 \pm 0.16$ & $0.31-0.83$ & USA, Norway \\
\hline Peanuts with red pellicle & 1 & 1.97 & - & USA \\
\hline Peanuts without pellicle & 5 & $0.84 \pm 0.43$ & $0.32-1.40$ & USA, Mali, China \\
\hline Pecans & 6 & $8 \cdot 33 \pm 1.50$ & $6.32-11.05$ & USA, Norway, Mexico \\
\hline Pistachios bought without outer shell & 2 & $0.89 \pm 0.11$ & $0.78-1.00$ & Norway, Unknown \\
\hline Walnuts with pellicle & 17 & $23.07 \pm 7.19$ & $10 \cdot 75-33 \cdot 29$ & USA, Norway, France, Italy, Unknown \\
\hline Walnuts without pellicle & 7 & $1.13 \pm 0.64$ & $0.46-2.58$ & Italy and Unknown \\
\hline
\end{tabular}


extract, respectively. In addition, copper-mediated LDL oxidation was inhibited by 14 and $84 \%$ in the presence of ellagic acid and walnut extract, respectively. LC-ELSD/MS analysis of the walnut extracts identified ellagic acid monomers, polymeric ellagitannins and other phenolics, mainly non-flavonoid compounds. These results demonstrate that walnut polyphenolics are effective inhibitors of in vitro LDL oxidation.

More recently, Chen et al. (2005) demonstrated that almond-pellicle flavonoids have a relatively high bioavailability in hamsters and increase the resistance of copper-mediated LDL in vitro and ex vivo. They also demonstrated that almond pellicle flavonoids act in synergy with vitamins $\mathrm{C}$ and $\mathrm{E}$.

Hatipoglu et al. (2004) investigated the effect of hazelnut oil on prooxidant-antioxidant status in rabbits fed a highcholesterol diet. As expected, a high-cholesterol diet significantly increased lipid and lipid peroxide levels in the plasma, liver and aorta and led to histopathological atherosclerotic changes in the aorta. Hazelnut oil supplementation reduced plasma, liver and aorta lipid peroxide levels and aorta cholesterol levels and ameliorated atherosclerotic lesions in the aortas of rabbits fed the high-cholesterol diet.

\section{Nut antioxidants and human intervention studies}

In a crossover trial with hypercholesterolemic patients, Zambon et al. (2000) showed that the mean total cholesterol level and the mean LDL cholesterol level decreased by 9.0 and $11.2 \%$, respectively, when patients were submitted to walnut dietary interventions. Moreover, the LDL particles were enriched with polyunsaturated fatty acids from walnuts but preserved their resistance to oxidation. Ros et al. (2004) showed that, in moderately hypercholesterolemic patients, walnuts significantly improved oxidative stress-related vascular endothelial function. In a study with a crossover design by Iwamoto et al. (2002), forty healthy individuals were randomly assigned to consume a walnut diet $(44-58 \mathrm{~g} / \mathrm{d})$ or a control diet for 4 weeks. Although plasma lipid levels improved significantly when subjects were fed the walnut diet (i.e. total cholesterol and serum apolipoprotein B concentrations and the ratio of LDL cholesterol to HDL cholesterol decreased significantly), LDL oxidizability was not influenced by the diets in this study.

Hyson et al. (2002) compared the effects of whole-almond versus almond-oil consumption on LDL oxidation in healthy men and women. Using a randomized crossover trial design, twenty-two normolipemic men and women replaced half of their fat intake with either whole almonds or almond oil for 6-week periods. Both treatments improved lipid parameters but neither treatment affected in vitro LDL oxidizability.

In a study by Durak et al. (1999), thirty healthy individuals consumed hazelnuts ( $1 \mathrm{~g} / \mathrm{d}$ per $\mathrm{kg}$ body weight) in addition to their normal daily diet for 30 days. These authors observed that hazelnut supplementation improved both lipid biomarkers and oxidative stress markers (i.e. malondialdehyde levels decreased and antioxidant capacity increased).

Inflammation is often a cause or effect of oxidative stress. A recent cross-sectional epidemiologic study of the consumption of nuts and seeds (based on the sum of self-reported frequency of 'almonds, walnuts, pecans, other nuts', 'sunflower, pinyon, other seeds', and 'peanuts, peanut butter') found lower levels of the circulating inflammatory markers
C-reactive protein, interleukin-6, and fibrinogen with a higher nut consumption (Jiang et al. 2006). Therefore, the results of this study support the hypothesis that nut antioxidants may reduce oxidative stress and, therefore, oxidativestress-related disease such as inflammation.

\section{Nut/peanut butter consumption is associated with a decreased incidence of cardiovascular diseases}

We have extended the analysis of Ellsworth et al. (2001) on the association between nut intake and death attributed to various diseases in the Iowa Women's Health Study (IWHS). As previously described (Ellsworth et al. 2001), this is a prospective cohort comprising 41836 women aged 55-69 years recruited via a baseline questionnaire (including a 127-item food frequency questionnaire) mailed in 1986 and followed through to 31 December 2001. Ellsworth et al. reported on nut consumption (based on self-reported frequency of a single item, 'nuts') in 34111 postmenopausal women in the first 12 years of follow-up, during which 3726 women died, 657 from coronary heart disease (CHD). After multiple adjustment, they compared two or more $28.5 \mathrm{~g}$ servings per week to less than one serving per month and found a $19 \%$ lower risk of death from CHD and a $12 \%$ lower risk of all-cause mortality. In the present study, we excluded women who were not postmenopausal and those with self-reported baseline heart disease or diabetes. Our study consisted of a 15-year follow-up of 31778 women, comprising a total of 472354 person years, with 5451 total deaths, including 1675 from cardiovascular disease (CVD) and 948 from coronary heart disease. We studied whether the risk of death due to coronary heart disease (CHD) or cardiovascular disease (CVD) is associated with the sum of self-reported 'nuts' and 'peanut butter' consumption in these women, who consume nuts as part of their normal diet.

The mean (SD) consumption of nuts/peanut butter in the IWHS was 2.37 servings/week (3.44), of which 0.75 (1.75) and $1.62(2.81)$ servings per week were nuts and peanut butter, respectively. Median intakes of nuts plus peanut butter and of each item separately are given in Table 4 for four intake levels.

After adjustment for age and energy intake, the hazard ratio for total death rates showed a U-shaped association with nut/ peanut butter consumption (Table 4). The hazard ratio was $0.89(\mathrm{CI}=0.81-0.97)$ and $0.81(\mathrm{CI}=0.75-0.88)$ for nut/peanut butter intake once per week and 1-4 times per week, respectively, but slightly higher for five or more times per week $(P=0.003$ for quadratic trend). Death attributed to CVD and CHD showed strong and consistent reductions with increasing nut/peanut butter consumption, with hazard ratios of $0.67(\mathrm{CI}=0.56-0.81)$ and $0.67(\mathrm{CI}=0.52-$ $0 \cdot 86$ ), respectively, for those reporting nut/peanut butter intake five or more times per week. These findings were slightly attenuated by additional adjustment. Most of the association with deaths from cardiovascular and coronary heart disease was attributable to peanut butter intake, which constituted more than two-thirds of the total nut/peanut butter intake in these data. Separate analyses confirmed that the findings for the single 'nuts' item were similar to those of Ellsworth et al. (2001) (data not shown). In particular, fewer than 1000 women reported consumption of nuts five 
or more times per week, so there was very little power to study daily consumption of nuts. No significant associations were observed between nut consumption and death from cancer or other diseases (data not shown).

The inverse association between nut intake and cardiovascular and coronary heart diseases in epidemiological studies may, or may not, be associated with antioxidants. Epidemiologic studies are not ideally suited for studying the role of specific nuts or biological mechanism. These studies follow disease rates according to broad consumption categories, such as 'nuts' and 'peanut butter' in the case of the Iowa Women's Health Study. Nevertheless, the findings presented here support the theory subscribed to in this paper, namely that the complex and rich mix of nut constituents protects against cardiovascular and perhaps other chronic diseases. Whether this protection is due to the antioxidant content of nuts cannot be ascertained from our data.

In conclusion, here we have identified several nuts as being among the dietary plants with highest contents of total antioxidants. Of the tree nuts, walnuts, pecans and chestnuts have the highest contents of antioxidants. In walnuts most of the antioxidants are located in the walnut pellicle. These data are in accordance with our present extended analysis of an earlier report on the association between nut intake and death attributed to various diseases in the Iowa Women's Health Study (Ellsworth et al. 2001). Death attributed to cardiovascular and coronary heart diseases showed strong and consistent reductions with increasing nut/peanut butter consumption. Interestingly, most of the association with deaths due to cardiovascular and coronary heart disease was attributable to peanut butter intake, which constituted more than two-thirds of the total nut intake in these data. While these findings support the theory subscribed to in this paper, namely that the complex and rich mix of nut constituents are protective against cardiovascular and perhaps other chronic diseases, they are not sufficiently specific to ascertain whether such protection is specific to the antioxidant content of nuts. The area is ripe for intensive studies, including controlled intervention studies, to clarify the extent to which the antioxidant content and other biochemical features of nuts may contribute to long-term health.

\section{Acknowledgements}

We thank Kari Holte for excellent technical assistance, and the Research Council of Norway, the Throne Holst foundation and the Norwegian Cancer Society for generous support to projects related to antioxidants and oxidative stress.

\section{References}

Albanes D, Heinonen OP, Taylor PR, et al. (1996) Alpha-Tocopherol and beta-carotene supplements and lung cancer incidence in the alpha-tocopherol, beta-carotene cancer prevention study: effects of base-line characteristics and study compliance. J Natl Cancer Inst 88, 1560-1570.

Anderson KJ, Teuber SS, Gobeille A, Cremin P, Waterhouse AL \& Steinberg FM (2001) Walnut polyphenolics inhibit in vitro human plasma and LDL oxidation. J Nutr 131, 2837-2842.

Beckman KB \& Ames BN (1998) The free radical theory of aging matures. Physiol Rev 78, 547-581. 
Benzie IFF \& Strain JJ (1996) The ferric reducing ability of plasma (FRAP) as a measure of "antioxidant power": the FRAP assay. Anal Biochem 239, 70-76.

Bjelakovic G, Nikolova D, Simonetti RG \& Gluud C (2004) Antioxidant supplements for prevention of gastrointestinal cancers: a systematic review and meta-analysis. Lancet 364, 1219-1228.

Blomhoff R (2005) Dietary antioxidants and cardiovascular disease. Curr Opin Lipidol 16, 47-54.

Brigelius-Flohe R, Kelly FJ, Salonen JT, Neuzil J, Zingg JM \& Azzi A (2002) The European perspective on vitamin E: current knowledge and future research. Am J Clin Nutr 76, 703-716.

Buettner GR (1993) The pecking order of free radicals and antioxidants: lipid peroxidation, $\alpha$-tocopherol and ascorbate. Arch Biochem Biophys 300, 535-543.

Cao G, Alessio HM \& Cutler RG (1993) Oxygen-radical absorbance capacity assay for antioxidants. Free Rad Biol Med 14, 303-311.

Chen C-Y, Milbury PE, Lapsley K \& Blumberg JB (2005) Flavonoids from almond skins are bioavailable and act synergistically with vitamins $\mathrm{C}$ and $\mathrm{E}$ to enhance hamster and human LDL resistance to oxidation. J Nutr 135, 1366-1373.

Cooper DA (2004) Carotenoids in health and disease: recent scientific evaluations, research recommendations and the consumer. J Nutr. 134, 221-224.

Dalton TP, Chen Y, Schneider SN, Nebert DW \& Shertzer HG (2004) Genetically altered mice to evaluate glutathione homeostasis in health and disease. Free Radic Biol Med. 37, 1511-1526.

Davidson A (1999) The Oxford Companion to Food. Oxford, UK: Oxford University Press.

DeLange RJ \& Glazer AN (1989) Phycoerythrin fluorescence-based assay for peroxyl radicals: a screen for biologically relevant protective agents. Anal Biochem 177, 300-306.

Dragland S, Senoo H, Wake K, Holte K \& Blomhoff R (2003) Several Culinary and Medicinal Herbs Are Important Sources of Dietary Antioxidants. J Nutr 133, 1286-1290.

Durak I, Köksal I, Kaçmaz M, Büyükkoçak S, Çimen BMY \& Öztürk HS (1999) Hazelnut supplementation enhances plasma antioxidant potential and lowers plasma cholesterol levels. Clinica Chimica Acta 284, 113-115.

Eidelman RS, Hollar D, Hebert PR, Lamas GA \& Hennekens CH (2004) Randomized trials of vitamin $\mathrm{E}$ in the treatment and prevention of cardiovascular disease. Arch Intern Med 164, 1552-1556.

Ellsworth JL, Kushi LH \& Folsom AR (2001) Frequent nut intake and risk of death from coronary heart disease and all causes in postmenopausal women: the Iowa Women's Health Study. Nutr Metab Cardiovasc Dis 11, 372-377.

Etminan M, Fitzgerald JM, Gleave M \& Hambers K (2005) Intake of Selenium in the Prevention of Prostate Cancer: a Systematic Review and Meta-analysis. Cancer Causes Control 16, $1125-1131$.

Fahey JW, Zhang Y \& Talalay P (1997) Broccoli sprouts: an exceptionally rich source of inducers of enzymes that protect against chemical carcinogens. Proc Natl Acad Sci 94, 10367-10372.

Frison-Norrie \& Sporns P (2002) Identification and quantification of flavonol glycosides in almond seedcoats using MALDI-TOF MS. J Afric Food Chem 50, 2782.

Gutteridge JM \& Halliwell B (2000) Free radicals and antioxidants in the year 2000. A historical look to the future. Ann N Y Acad Sci 899, $136-147$.

Halliwell B (1996) Antioxidants in human health and disease. Annu Rev Nutr 16, 33-50.

Halvorsen BL, Holte K, Myhrstad MC, et al. (2002) A systematic screening of total antioxidants in dietary plants. J Nutr 132, 461-471.

Hatipoglu A, Kanbagli O, Balkan J, Kucuk M, Cevikbas U, Aykac-Toker G, Berkkan H \& Uysal M (2004) Hazelnut oil administration reduces aortic cholesterol accumulation and lipid peroxides in the plasma, liver, and aorta of rabbits fed a high-cholesterol diet. Biosci Biotechnol Biochem 68, 2050-2057.

Hyson DA, Schneeman BO \& Davis PA (2002) Almonds and almond oil have similar effects on plasma lipids and LDL oxidation in healthy men and women. J Nutr 132, 703-707.

Iwamoto M, Imaizumi K, Sato M, Hirooka Y, Sakai K, Takeshita A \& Kono M (2002) Serum lipid profiles in Japanese women and men during consumption of walnuts. Eur J Clin Nutr 56, 629-637.

Jacobs DR Jr \& Steffen LM (2003) Nutrients, foods, and dietary patterns as exposures in research: a framework for food synergy. Am $J$ Clin Nutr 78, 508-513.

Jiang R, Jacobs DR, Mayer-Davis E, Szklo M, Herrington D, Jenny N, Kronmal R \& Barr RG (2006) Nut and Seed Consumption and Inflammatory Markers in the Multi-Ethnic Study of Atherosclerosis. Am J Epidemiol, 163, 222-231.

Joseph JA, Shukitt-Hale B, Denisova NA, Bielinski D, Martin A, McEwen JJ \& Bickford PC (1999) Reversals of age-related declines in neuronal signal transduction, cognitive and motor behavioral deficits with diets supplemented with blueberry, spinach or strawberry dietary supplementation. J Neurosci 19, 8114-8121.

Lindsay DG \& Astley SB (2002) European research on the functional effects of dietary antioxidants - EUROFEDA. Mol Aspects Med 23, 1-38.

Lou H, Yuan H, Yamazaki Y, Sasaki T \& Oka S (2001) Alklaoids and flavonoids from peanut skin. Planta Med 67, 345-349.

McEligot AJ, Yang S \& Meyskens FL Jr (2005) Redox regulation by intrinsic species and extrinsic nutrients in normal and cancer cells. Annu Rev Nutr 25, 261-295.

McCord JM (2000) The evolution of free radicals and oxidative stress. Am J Med 108, 652-659.

Miller NJ \& Rice-Evans CA (1996) Spectrophotometric determination of antioxidant activity. Redox Rep 2, 161-168.

Moskaug JO, Carlsen H, Myhrstad MC \& Blomhoff R (2005) Polyphenols and glutathione synthesis regulation. Am J Clin Nutr 81, $277-283$

Mukuddem-Petersen J, Oosthuizen W \& Jerling JC (2005) A systematic review of the effects of nuts on blood lipid profiles in humans. J Nutr 135, 2082-2089.

Omenn GS, Goodman GE, Thornquist MD, et al. (1996a) Risk factors for lung cancer and for intervention effects in CARET, the Beta-Carotene and Retinol Efficacy Trial. J Natl Cancer Inst 88, $1550-1559$.

Omenn GS, Goodman GE, Thornquist MD, et al. (1996b) Effects of a combination of beta carotene and vitamin A on lung cancer and cardiovascular disease. $N$ Engl J Med 334, 1150-1155.

Packer L, Weber SU \& Rimbach G (2001) Molecular aspects of alpha-tocotrienol antioxidant action and cell signalling. $J$ Nutr 131, 369S-373S.

Rapola JM, Virtamo J, Ripatti S, Huttunen JK, Albanes D, Taylor PR \& Heinonen OP (1997) Randomised trial of alpha-tocopherol and betacarotene supplements on incidence of major coronary events in men with previous myocardial infraction. Lancet 349, 1715-1720.

Ros E, Núñez I, Pérez-Heras A, Serra M, Gilabert R, Casals E \& Deulofeu R (2004) A walnut diet improves endothelial function in hypercholesterolemic subjects: a randomized crossover trial. Circulation 109, 1609-1614.

Sang S, Lapsley K, Jeong WS, lachance PA, Ho CT \& Rosen RT (2002) Antioxidative phenolic compounds isolated from almond skins (Prunus amygdalus Batsch). J Agric Food Chem 50, 2459-2463.

Selverstone Valentine J, Doucette PA \& Zittin Potter S (2005) Copper-zinc superoxide dismutase and amyotrophic lateral sclerosis. Annu Rev Biochem 74, 563-593.

Shekelle PG, Morton SC, Jungvig LK, et al. (2004) Effect of supplemental vitamin $\mathrm{E}$ for the prevention and treatment of cardiovascular disease. J Gen Intern Med 19, 380-389.

Sies H (1997) Oxidative stress: oxidants and antioxidants. Exp Physiol 82, 291-295. 
Stanner SA, Hughes J, Kelly CN \& Buttriss J (2004) A review of the epidemiological evidence for the 'antioxidant hypothesis'. Public Health Nutr 7, 407-422.

Svilaas A, Sakhi AK, Andersen LF, Svilaas T, Strom EC, Jacobs DR Jr, Ose L \& Blomhoff R (2004) Intakes of antioxidants in coffee, wine, and vegetables are correlated with plasma carotenoids in humans. J Nutr 134, 562-567.

Talalay P (2000) Chemoprotection against cancer by induction of phase 2 enzymes. Biofactors 12, 5-11.

Trevisan MT, Pfundstein B, Haubner R, Wurtele G, Spiegelhalder B, Bartsch H, Owen RW (2006) Characterization of alkyl phenols in cashew (Anacardium occidentale) products and assay of their antioxidant capacity. Food Chem Toxicol 44, 188-97.

Wu X, Beecher GR, Holden JM, Haytowitz DB, Gebhardt SE \& Prior RL (2004) Lipophilic and hydrophilic antioxidant capacities of common foods in the United States. J Agric Food Chem 52, 4026-4037.

Zambon D, Sabate J, Munoz S, Campero B, Casals E, Merlos M, Laguna JC \& Ros E (2000) Substituting walnuts for monounsaturated fat improves the serum lipid profile of hypercholesterolemic men and women. A randomized crossover trial. Ann Intern Med 132, $538-546$. 